\title{
Mercado y conductas anticompetitivas
}

\author{
Rosa Liliana Dávila Broncano
}

Corte Superior de Justicia de Lima, Lima, Perú

RESUMEN. El presente artículo desarrolla, preliminarmente, un resumen de los conceptos de mercado y competencia, con el fin de comprender y analizar la problemática de las conductas anticompetitivas que vulneran a todos los miembros de la sociedad (tanto demandantes como oferentes). Del mismo modo, se observan ejemplos de cómo este tipo de prácticas ha sido regulado por la legislación nacional e internacional.

PALABRAS CLAVE: mercado / competencia / posición de dominio / prácticas colusorias

\section{Market and anticompetitive behavior}

Aвstract. This article develops, preliminarily, a brief summary of the concepts of market and competition to understand and analyze the problem of anticompetitive behavior that harm all members of society (both demanders and suppliers). Likewise, examples of how said behavior has been regulated by national and international legislations are examined. 


\section{INTRODUCCIÓN}

Cuando hablamos de mercado, muchos lo consideran un tema nuevo o de difícil análisis, relacionándolo básicamente con conocimientos en economía. Esto es cierto en gran parte; sin embargo, el mercado comparte sus orígenes con la humanidad y siempre ha formado parte de nuestro quehacer diario.

Las personas, en su vida, tienen muchas necesidades que cubrir y no pueden hacerlo solas, por lo que surge la necesidad de especializarse en las actividades que mejor realizan, por ejemplo, agricultores, ganaderos, mineros, médicos, ingenieros, profesores, etcétera. Posteriormente, los productos y servicios que generan ingresan al tránsito, a su intercambio, por un costo (comercio). Esto es el mercado: el espacio en el que se producen estos intercambios. Aparecen así las figuras de proveedor y consumidor, que son el eje, las funciones principales respecto a las cuales gira el mercado.

El continuo avance de la cultura, la industria y la tecnología procura el desarrollo de los pueblos, que trae consigo el crecimiento del mercado. Esto es, más productos que intercambiar y su permanente perfeccionamiento, más consumidores, más proveedores $\mathrm{y}$, como consecuencia, el crecimiento de la actividad económica de los pueblos y la satisfacción cada vez mejor de sus necesidades.

Entonces los mercados vienen a constituir un buen mecanismo para organizar la actividad económica, a pesar de que los operadores del mismo buscan su propio provecho; sin embargo, las economías de mercado han demostrado ser capaces de organizar con notable éxito la actividad económica de una forma que promueve el bienestar económico general. (Mankiw, 2007, p. 8)

\section{CONCEPTO De Mercado}

Son muchas, pero a la vez muy similares, las definiciones de mercado. Nosotros nos quedaremos con una adaptada a nuestro entender, como el espacio en donde se producen los intercambios de bienes y servicios, con la participación de los proveedores u ofertantes y los consumidores, a quienes se les satisface sus demandas o necesidades a cambio de una contraprestación (el precio que se paga), que guarda relación con el valor de su producción y el grado de necesidad del mismo. El precio es 
un mecanismo de gobierno, que regula a los que compran y a los que venden para que los dos perciban que ganan.

Para los economistas, un mercado es el conjunto de compradores (demandantes) y vendedores (oferentes) de un determinado bien o servicio. En los mercados se define cuánto de dicho bien se compra y se vende (el volumen de las transacciones) y a qué precio.

El acto de comprar tiene implícito un costo de oportunidad claro: renunciar a consumir los bienes que potencialmente podría haber comprado con los recursos que está destinando a adquirir el bien. De idéntica manera, los vendedores toman decisiones importantes que los llevan a ofrecer cierta cantidad del bien que se comercializa en este mercado a cierto precio. Invierten recursos en su producción en lugar de darle otro destino a estos. Por ejemplo, podrían dedicar dichos recursos al consumo en lugar de la inversión, o podrían asignarlos a la producción de otro bien. Así, toda decisión de producción tiene implícitos ciertos costos de oportunidad. Por lo tanto, cuando compradores $\mathrm{y}$ vendedores negocian en un mercado, han tomado previamente decisiones económicas muy relevantes [...]. Algunos mercados funcionan en un espacio y tiempo específicos [...] y negocian el valor al que están dispuestos a vender y comprar cierta cantidad del bien. Otros mercados tienen funcionamientos menos personalizados: compradores y vendedores nunca interactúan físicamente entre ellos, por ejemplo, las ventas y compras que se realizan vía internet. Lo que define la existencia de un mercado es la presencia de oferentes y demandantes potenciales de un determinado bien, independientemente de la organización específica que asuma dicho mercado. (Troncoso, 2012, p. 10)

\section{Mercado libre}

Se conoce como mercado libre a aquel sistema económico dentro del cual la oferta y la demanda establecen de manera exclusiva los precios, sin que participe ningún tipo de regulación o control. Es la mejor forma de que un país progrese; si no existe libertad, no se puede competir. El mercado se regula solo; la intervención del Estado debe ser residual.

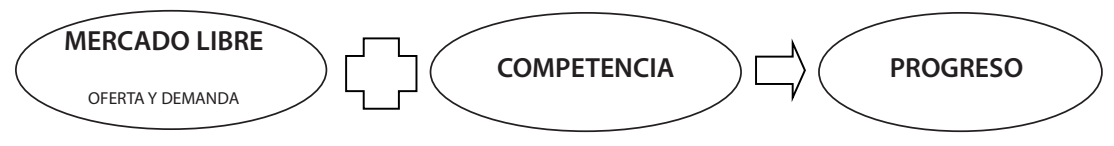


Troncoso (2012) describe así los mercados libres:

Uno de los principales elementos que caracterizan a los mercados competitivos es la gran cantidad de compradores (demandantes) y vendedores (oferentes) que existe en el mercado, también conocida como atomicidad de los mercados, ya que "gran cantidad" se asocia, en consecuencia, a cierto tamaño relativamente pequeño de los agentes que conforman esos mercados. Esto le otorga cierto matiz de rivalidad entre demandantes, por un lado, y oferentes, por otro, que implica que ningún comprador ni vendedor pueda individualmente influir en la determinación de los precios, siendo su acción conjunta, la de todos y cada uno, lo que determinará el precio del mercado. Es por ello que decimos que en los mercados competitivos el precio lo fija "el mercado" o que tanto compradores como vendedores son precio aceptantes. La participación de un consumidor o una empresa en un mercado en el cual cada participante representa una porción insignificante del agregado es lo que conduce a que individualmente no se pueda tener influencia en el precio [...]. Como adelantamos, estas condiciones de los mercados competitivos llevan a que las cantidades y precios de los mercados se determinen por el libre juego de la oferta y la demanda, sin la influencia particular de ninguno de sus participantes: ni empresas ni consumidores, sino que surge por lo que algunos denominan la fuerza más pura de la competencia. (pp. 65-66)

\section{Competencia}

Ubicados en el mercado, con la participación de un sinnúmero de proveedores y aún más de consumidores, nos encontramos con la competencia, figura que condiciona el funcionamiento del mercado, genera trabajo, mejora la economía, beneficia a los consumidores $\mathrm{y}$, por supuesto, también a los proveedores. Si no hay competencia, se perjudica al consumidor, en tanto no hay avances, suben los precios y baja la calidad de los productos, ya que no se impulsa el esfuerzo por brindar un buen producto o servicio. Para Espinoza (2014): "La competencia viene a ser un proceso natural que se da en el mercado y que puede ser definida como la rivalidad de empresas por obtener las preferencias de los consumidores e incrementar su participación en el mercado" (p. 2). Surge, entonces, una interrogante: ¿existe la competencia perfecta? Si bien es el anhelo o punto al cual se quisiera llegar, podemos decir que, en un mercado ideal, cada empresa (proveedor) debe esforzarse por que su producto o servicio se encuentre en las mejores condiciones para que atraiga la decisión de consumo. 
En un mercado que funciona bajo condiciones de competencia, las condiciones de venta se determinan como resultado de la confluencia de la demanda de los consumidores o clientes por productos o servicios con la oferta de bienes por parte de los productores y comercializadores. Es decir, los agentes económicos interactúan en múltiples tratativas y negociaciones comerciales $\mathrm{y}$, a través de ellas, se van definiendo las condiciones de venta de los bienes sin que productores, comercializadores o consumidores tengan la capacidad de determinarlas de modo unilateral o por su sola voluntad. (Quintana, 2013, p. 14)

Por tanto, en un mercado competitivo no hay perdedores, sino que resultan beneficiados tanto el Estado, las empresas y, especialmente, los consumidores. Los proveedores compiten (competitividad) por la eficiencia en su producción, aspirando a ser la mejor opción en el mercado, con lo cual incrementan sus ingresos, o bien mejoran su imagen cuando sus fines no son lucrativos. Por su parte, los consumidores obtienen mejores productos con menores precios, mejorando con ello su calidad de vida, al cubrir sus necesidades con mejores productos o servicios. Además, el Estado recauda mayores ingresos, que puede invertir mejor en el progreso y calidad de los servicios que presta a los ciudadanos.

La competencia es, en realidad, la sangre vital de cualquier sistema económico dinámico. Más aún, la competencia es el fundamento de la calidad de vida y está vinculada a los aspectos más trascendentes de la existencia humana desde el punto de vista educacional, civil, religioso, cultural y, además, económico. Esta es la herencia intelectual de los debates que han ocurrido en los últimos siglos con miras a explicar las consecuencias benéficas de la competencia, el mayor descubrimiento de este milenio. (Becker, 2002, p. 61)

La idea es que, en el mercado, las condiciones de la oferta no pueden ser establecidas por una sola empresa. En este sentido, la competencia perfecta demanda ciertos requisitos para impedir que esta situación se produzca. El primero es la necesidad de que existan en el mercado productos homogéneos o muy similares que puedan ser escogidos por los consumidores sin importar quién sea el proveedor, porque cualquiera de ellos cumple con sus expectativas. En segundo lugar, tenemos la presencia de vendedores y compradores en gran cantidad, de manera que todos compran y venden, con lo cual no se produce disparidad en las operaciones especialmente de los proveedores, y no se produce un desequilibrio en el precio que puede perjudicar a ambos operadores del mercado. Asimismo, se requiere que todos cuenten con información 
simétrica del producto, que debe ser perfecta y total, para que el consumidor tome su decisión de compra con conocimiento de las características, beneficios e, inclusive, deficiencias del producto. Finalmente, está la libertad de ingreso y salida del mercado; se tiene que brindar facilidades tanto administrativas como de costos (sin barreras burocráticas) para que las empresas o los inversionistas nacionales e internacionales decidan invertir en la economía de un país, pero, del mismo modo, se puedan ir cuando así lo determinen (retiro de mercado).

Como se dijo, esto es lo ideal. Pero encontrar una competencia perfecta está muy alejado de la realidad, es casi imposible. Lo que vemos, con seguridad, son las llamadas "fallas de mercado" o "poder de mercado", esto es, la existencia de mercados que no compiten, como el monopólico, llamado también oligopólico. Este tipo de mercados no genera equilibrio (eficiencia, precio y producción), en tanto hay un solo proveedor (productor o vendedor) que decide el precio de acuerdo con la demanda y, por ello, puede decidir también la cantidad que produce, al estar en la posibilidad de generar escasez para elevar los precios.

\section{LIBRE COMPETENCIA}

En el Perú, el Decreto Legislativo 757, Ley Marco para el Crecimiento de la Inversión Privada, en su artículo 4, respecto de la libre competencia, señala:

[La libre competencia] implica que los precios en la economía resultan de la oferta y la demanda, de acuerdo con lo dispuesto en la Constitución y las Leyes. Los únicos precios que pueden fijarse administrativamente son las tarifas de los servicios públicos, conforme a lo que se disponga expresamente por Ley del Congreso de la República.

Esta norma es clave porque obliga a procurar un mercado eficiente, en donde los operadores, como se dijo antes, presenten en el mercado los mejores productos que satisfagan las necesidades de los consumidores. Solo ello repercutirá en que su oferta sea aceptada permanentemente, de manera que obtengan mayor consumo y puedan mantener sus precios al alcance de los destinatarios. Nos encontramos así ante un círculo eficiente: consumidores que demandan productos de calidad, proveedores que ofrecen productos de calidad considerando las necesidades y requerimientos de los consumidores, y precios que pueden mantenerse bajos por la mayor demanda, que genera más producción. 


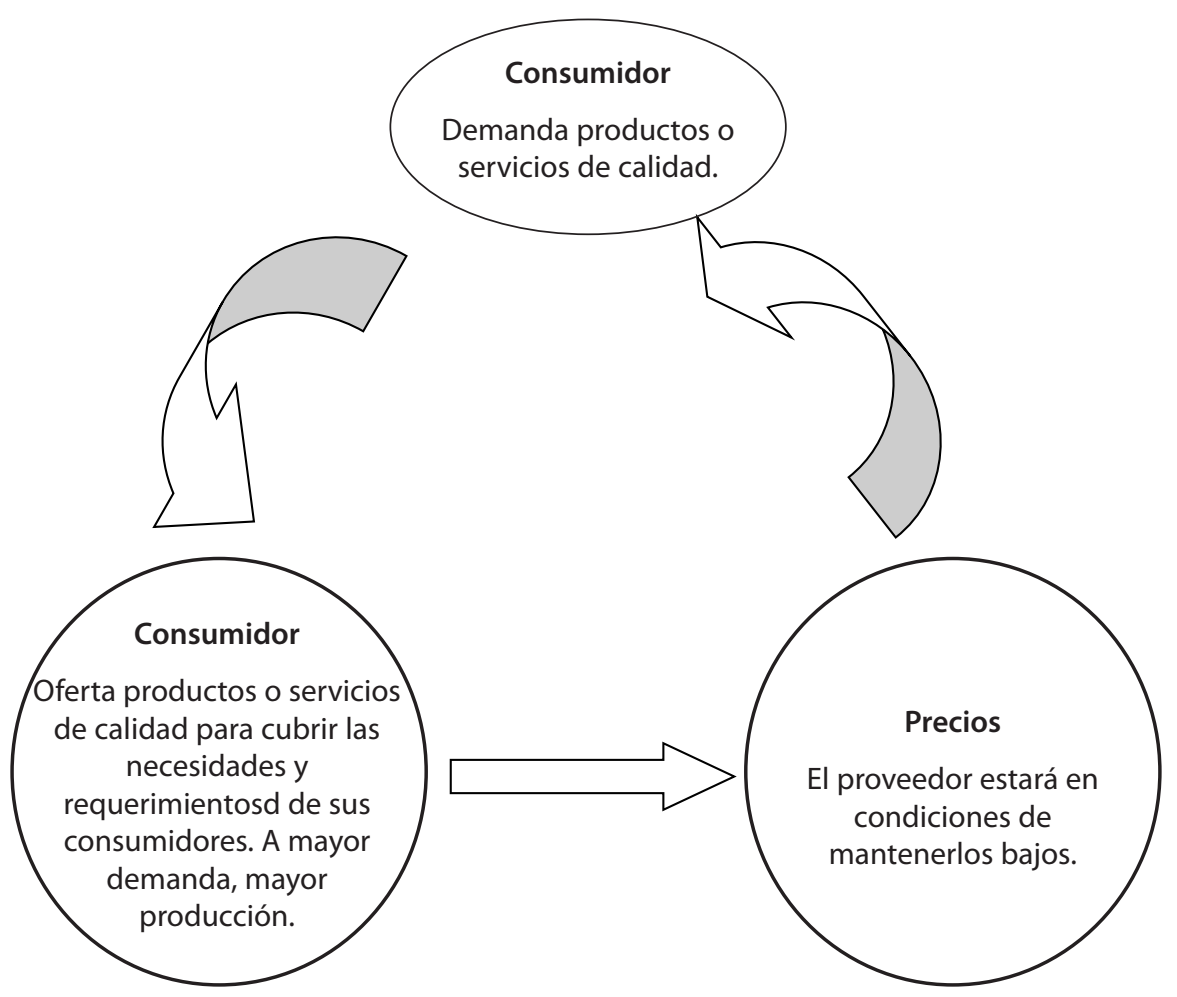

\section{CONDUCTAS ANTICOMPETITIVAS}

Las conductas anticompetitivas son aquellas que destruyen la competencia perfecta en el mercado, las cuales, en vez de privilegiar la honradez, la transparencia, el cumplimiento $\mathrm{u}$ observancia de las normas y las buenas prácticas, dan paso a conductas embusteras, engañosas, traicioneras, desleales.

Este tema históricamente fue abordado en el Tratado de Roma de 1957, que fue el Tratado Constitutivo de la Comunidad Europea. Se acordó que la base de su progreso económico debía girar en el establecimiento de un mercado común mediante la realización de políticas de un desarrollo armonioso, equilibrado y sostenible de sus actividades económicas; un alto grado de competitividad; la elevación del nivel y calidad de vida; la cohesión económica y social, así como la solidaridad entre sus Estados miembros, entre otras. 
Para alcanzar sus fines, establecieron conductas que se debían respetar. Entre ellas, las que guardan relación con nuestro tema son las siguientes: se prohibieron restricciones cuantitativas a la entrada y salida de las mercancías, así como de cualesquiera otras medidas de efecto equivalente, en un mercado interior caracterizado por la supresión, entre los Estados miembros, de los obstáculos a la libre circulación de mercancías, servicios y capitales; se estableció un régimen que garantice que la competencia no será falseada en el mercado interior; se dispuso la aproximación de las legislaciones nacionales en la medida necesaria para el funcionamiento del mercado común; se fortaleció la competitividad de la industria de la Comunidad; se contribuyó al fortalecimiento de la protección de los consumidores; se decidió el respeto al principio de una economía de mercado abierta y de libre competencia. Los principios rectores fueron el respeto a los precios estables, finanzas públicas y condiciones monetarias sólidas y balanza de pagos estable.

El Tratado de Roma de 1957 se ocupó de manera particular de los consumidores en su artículo 153, donde se comprometió a garantizarles un alto nivel de protección, además de su salud y seguridad de sus intereses económicos, y promover, además, su derecho a la información y a organizarse para salvaguardar sus intereses. Este tratado sufrió modificaciones en el tiempo (Tratado Constitutivo de la Unión Europea y Tratado de Funcionamiento de la Unión Europea), que establecieron normas de competencia aplicables a las empresas. En su artículo 101, respecto a nuestro tema, señala que serían incompatibles con el mercado interior y quedarían prohibidos todos los acuerdos entre empresas, las decisiones de asociaciones de empresas y las prácticas concertadas que puedan afectar el comercio entre los Estados miembros y que tengan por objeto o efecto impedir, restringir o falsear el juego de la competencia dentro del mercado interior. En particular, se refiere a los que consistan en fijar directa o indirectamente los precios de compra o de venta, $\mathrm{u}$ otras condiciones de transacción; limitar o controlar la producción, el mercado, el desarrollo técnico o las inversiones; repartirse los mercados o las fuentes de abastecimiento; aplicar a terceros contratantes condiciones desiguales para prestaciones equivalentes, que ocasionen una desventaja competitiva; subordinar la celebración de contratos a la aceptación, por los otros contratantes, de prestaciones suplementarias que, por su naturaleza o según los usos mercantiles, no guarden relación alguna con el objeto de dichos contratos. 
Por la globalización, el mercado mundial ha sufrido una transformación que se debe, fundamentalmente, a la liberalización de las economías y al incesante avance de la tecnología en todos los aspectos: comunicación (telecomunicaciones, transporte), energía y acceso casi ilimitado a todo tipo de información. Estos cambios han traído consigo la reducción de costos, en especial, en las transacciones, pues ya no es necesario el traslado físico de los operadores del mercado; ahora, pueden celebrarse negociaciones a gran distancia y a una velocidad increíble (en tiempo real).

El Acuerdo de Promoción Comercial entre Perú y Estados Unidos, vigente desde el 1 de febrero del 2009, así como otros acuerdos comerciales, tuvieron un impacto positivo en nuestra sociedad, dado que el Estado peruano asumió el compromiso de tomar acciones que garantizaran que estos tratados beneficien a los consumidores y empresas nacionales. Por esta razón, el Congreso de la República delegó al Poder Ejecutivo la facultad de legislar, entre otras materias, la facilitación del comercio, la mejora del marco regulatorio, el fortalecimiento institucional, la simplificación administrativa, la modernización del Estado, la mejora de la administración de justicia en materia comercial y contenciosoadministrativa, y la promoción de la inversión privada.

De esta manera, ingresó a nuestra legislación el Decreto Legislativo 1034, que aprueba la Ley de Represión de Conductas Anticompetitivas, para prohibirlas y sancionarlas, con la finalidad de promover la eficiencia económica en los mercados para el bienestar de los consumidores. Es aplicable a las conductas que produzcan o puedan producir efectos anticompetitivos en todo o en parte del territorio nacional, aun cuando dicho acto se haya originado en el extranjero.

Las figuras que reconoce el Decreto Legislativo 1034 como anticompetitivas son estas:

- Abuso de la posición de dominio

- Prácticas colusorias horizontales

- Prácticas colusorias verticales

\section{Abuso de posición de dominio}

Para ingresar al tema, primero debemos definir qué es un mercado relevante, en tanto es allí donde se pueden realizar las prácticas anticompetitivas. Así, de acuerdo con lo establecido por el artículo 6 del 
Decreto Legislativo 1034, el mercado relevante está integrado por el mercado de producto y el mercado geográfico. El mercado de producto relevante es, por lo general, el bien o servicio materia de la conducta investigada y sus sustitutos (se determinan con la evaluación, entre otros aspectos, de las preferencias de los consumidores, características, usos, precios, posibilidades tecnológicas y tiempo requerido para la sustitución). Por mercado geográfico relevante se entiende el conjunto de zonas geográficas donde están ubicadas las fuentes alternativas de aprovisionamiento del producto relevante (para determinarlas se evalúa, entre otros, los costos de transporte y las barreras al comercio existente).

Asimismo, corresponde fijar qué se entiende por posición de dominio, para luego establecer cuáles son las conductas en que se hace abuso de dicha posición. El artículo 7 de la norma en referencia señala que la posición de dominio en el mercado ocurre cuando un agente económico tiene la posibilidad de restringir, afectar o distorsionar en forma sustancial las condiciones de la oferta o demanda, sin que sus competidores, proveedores o clientes puedan contrarrestarla en ese momento o en un futuro inmediato. Esto se debe a factores como una participación significativa en el mercado relevante; las características de la oferta y la demanda de los bienes o servicios; el desarrollo tecnológico o servicios involucrados; el acceso de competidores a fuentes de financiamiento y suministro, así como a redes de distribución; la existencia de barreras a la entrada legal, económica o estratégica; la existencia de proveedores, clientes o competidores, y el poder de negociación de estos.

La misma norma se encarga de precisar que el solo hecho de tener una posición de dominio no implica un ilícito; ello sucede cuando se produce un exceso en el ejercicio del poder en el mercado. El abuso de dicha posición se encuentra cuando el operador realiza conductas que atentan contra el libre mercado y la libre competencia, perturbando el desarrollo de una "competencia perfecta", porque tiene la posibilidad de restringir, afectar o distorsionar en forma sustancial las condiciones de la oferta y la demanda en el mercado relevante. Con la intención, lógicamente, de incrementar sus ingresos o beneficios, lesiona a sus competidores para disminuirlos o sacarlos de la competencia, y con ello hasta del mercado.

En primer lugar, el abuso de posición de dominio se produce cuando un agente económico que tiene posición dominante en el mercado actúa de manera indebida, con el fin de obtener beneficios y causar perjuicios a sus competidores, reales o potenciales, directos o indirectos, que no 
hubieran sido posibles de no existir la posición de dominio. (Gagliuffi, 2013, p. 142)

Nuestra legislación considera como conductas reprochables de abuso de posición de dominio las de efecto exclusorio, cuya finalidad es impedir el ingreso, apartar, separar, aislar, eliminar o expulsar a los competidores. Entre ellas tenemos las siguientes:

a. Negarse injustificadamente a satisfacer demandas de compra o adquisición, o a aceptar ofertas de venta o prestación, de bienes o servicios.

b. Aplicar, en las relaciones comerciales o de servicio, condiciones desiguales para prestaciones equivalentes, que coloquen de manera injustificada a unos competidores en situación desventajosa frente a otros.

c. Subordinar la celebración de contratos a la aceptación de prestaciones adicionales que, por su naturaleza o arreglo al uso comercial, no guarden relación con el objeto de tales contratos.

d. Obstaculizar de manera injustificada a un competidor la entrada o permanencia en una asociación u organización de intermediación.

e. Establecer, imponer o sugerir contratos de distribución o venta exclusiva, cláusulas de no competencia o similares, que resulten injustificados.

f. Utilizar de manera abusiva y reiterada procesos judiciales o procedimientos administrativos, cuyo efecto sea restringir la competencia.

g. Incitar a terceros a no proveer bienes o prestar servicios, o a no aceptarlos.

h. En general, aquellas conductas que impidan o dificulten el acceso o permanencia de competidores actuales o potenciales en el mercado por razones diferentes a las de una mayor eficiencia económica.

Este último inciso es una lista abierta (numerus apertus), en tanto da acceso a nuevas conductas que puedan considerarse como abusivas. Esto resulta positivo porque la realidad enseña que con el tiempo surgen nuevas conductas transgresoras que necesitan ser combatidas. 
A continuación, se transcribe un extracto de una resolución del Tribunal de Defensa de la Competencia y de la Propiedad Intelectual, respecto a prácticas exclusorias:

DENUNCIANTE: LLAMA GAS S. A.

DENUNCIADA: PETRÓLEOS DEL PERÚ - PETROPERÚ S. A.

\section{MATERIA: LIBRE COMPETENCIA, ABUSO DE POSICIÓN DE DOMINIO, DISCRIMINACIÓN}

Se CONFIRMA la Resolución 010-2012/ST-CLC-INDECOPI del 18 de junio del 2012, expedida por la Secretaría Técnica de la Comisión de Defensa de la Libre Competencia, que declaró improcedente la denuncia interpuesta por Llama Gas S. A. contra Petróleos del Perú - Petroperú S. A. por un presunto abuso de posición de dominio en la modalidad de discriminación, supuesto de infracción previsto en el artículo 10.2, literal b), del Decreto Legislativo 1034, Ley de Represión de Conductas Anticompetitivas. La razón es que de la denuncia y de la información recabada en las indagaciones preliminares no se advierte la existencia de indicios razonables que permitan determinar que la empresa denunciada ostenta posición de dominio en el mercado de comercialización mayorista de gas licuado de petróleo en Talara, el Callao y Pisco. De igual modo, tampoco se verifican indicios razonables de un efecto exclusorio como consecuencia de la conducta denunciada, en la medida que Petróleos del Perú - Petroperú S. A. no constituye un competidor real o potencial, directo o indirecto de la denunciante. (Expediente 001-2012/CLC M-SDC-02/1A, 3 de abril del 2013)

\section{Sobre el efecto exclusorio}

39. Cabe precisar que, si bien no existen indicios de que Petroperú ostenta posición de dominio en el mercado relevante definido de manera preliminar, en la misma orientación de lo resuelto en primera instancia, corresponde verificar si la conducta imputada por Llama Gas podría tener un efecto exclusorio, requisito que también es concurrente para que pueda configurarse un abuso de posición de dominio en la modalidad de discriminación.

40. Posición de dominio solo podrá consistir en conductas de efecto exclusorio. Un abuso de posición de dominio exclusorio es aquel que afecta directamente la dinámica de la competencia, pues impide el acceso de competidores del dominante al mercado o dificulta su permanencia en él.

42. La identificación de las conductas de abuso de posición de dominio con un efecto de exclusión de competidores del dominante guarda directa relación con la finalidad del Decreto Legislativo 1034 contenida en su artículo 1, esto es, la prohibición de conductas que dañen el 
proceso competitivo y, por ende, la eficiencia económica. Las prácticas exclusorias o prácticas de exclusión son aquellas mediante las cuales un monopolista $\mathrm{u}$ operador dominante ejerce su poder monopólico para disuadir la entrada de potenciales competidores al mercado o impedir que estos incrementen su producción. Al respecto, Hovenkamp anota: “El juez Wyzanski sabiamente definió el 'ejercicio' del poder de monopolio como una práctica 'de exclusión', es decir, una práctica que disuade a los potenciales rivales de entrar en el mercado del monopolista, o a los rivales actuales de aumentar su producción en respuesta al incremento de los precios del monopolio. Las ventas del producto del monopolista a un precio de monopolio no son una práctica de 'exclusión' [...]. 'Las prácticas de exclusión' son actos por el monopolista diseñados para disuadir a posibles competidores de entrar en el campo, o para evitar que los competidores incrementen su producción".

43. Asimismo, el artículo 10.5 del Decreto Legislativo 103427 establece expresamente que no constituye abuso de posición de dominio el simple ejercicio de dicha posición sin afectar a competidores reales o potenciales. Con esta disposición, se incide en la exigencia del carácter exclusorio del abuso de posición de dominio, siendo que el establecimiento de precios por parte de una empresa dominante a un nivel que implique únicamente la maximización de sus beneficios es una conducta que solo representa el ejercicio de dicha posición, pero que no se encuentra en el ámbito de aplicación de la ley, dado que no afecta el proceso competitivo al no estar dirigida a competidores actuales o potenciales del dominante.

44. Dentro de las modalidades de abuso de posición de dominio, el literal b) del artículo 10.2 de la ley recoge la figura de la discriminación, al señalar que califica como un supuesto de abuso de dicha posición el que un agente dominante aplique, en las relaciones comerciales o de servicio, condiciones desiguales para prestaciones equivalentes que coloquen de manera injustificada a unos competidores en situación desventajosa frente a otros.

45. Al respecto, debe tenerse presente que para que se configure dicha infracción no solo se requiere que el sujeto infractor ostente posición dominante. Conforme se advierte de las disposiciones del Decreto Legislativo 1034 antes señaladas, para la configuración de una conducta anticompetitiva también es necesario que la conducta cuestionada genere o sea susceptible de generar un efecto exclusorio, es decir que excluya a competidores del mercado o que impida el ingreso a este último de potenciales rivales del presunto agente dominante. [...] Este el caso de las denominadas prácticas explotativas, entre ellas, la imposición de los denominados "precios excesivos". 
46. La exigencia del efecto exclusorio en las prácticas de abuso de posición de dominio se encuentra intrínsecamente ligada con la existencia de una relación de competencia actual o potencial entre el dominante y el agente económico presuntamente afectado con la conducta anticompetitiva. En la medida que la finalidad de las prácticas de exclusión es que el dominante mantenga su posición en el mercado o que pueda trasladar dicha posición a otro mercado a través de la exclusión de competidores actuales o potenciales, el presupuesto de ello es que se presente - aunque sea de manera potencial - una relación de competencia.

47. La Resolución 010-2012/ST-CLC-INDECOPI consideró que no existían indicios razonables de que la presunta práctica denunciada haya permitido a Petroperú obtener beneficios o generar perjuicios a sus competidores reales o potenciales, directos o indirectos. Ello debido a que Llama Gas no tiene una relación de competencia directa o indirecta con la denunciada, pues la recurrente se encarga principalmente del envasado del GLP y la venta minorista del producto, mientras que Petroperú se dedica al suministro y la venta mayorista del GLP.

\section{Prácticas colusorias}

Una conducta colusoria es todo acuerdo, decisión o recomendación colectiva, o práctica concertada o conscientemente paralela, que produzca o pueda producir el efecto de impedir, restringir o falsear la competencia (Autoridad Vasca de la Competencia, 2013).

Las conductas colusorias se caracterizan legalmente no por la utilización de un medio en especial - puesto que se refiere genéricamente a "prácticas, conductas o recomendaciones" - , sino por sus efectos: "restringir, limitar, obstaculizar, distorsionar o impedir la competencia". Es indiferente $[. .$.$] que el efecto sea actual o potencial, pero sí exige que recaiga$ sobre lo que denomina "mercado relevante". (López Rodríguez, 2008)

\section{Prácticas colusorias horizontales}

Las prácticas colusorias horizontales son las que se producen entre agentes económicos competidores que realizan acuerdos, toman decisiones, hacen recomendaciones o conciertan prácticas entre sí con la finalidad de restringir, impedir o falsear la libre competencia. El artículo 11 del Decreto Legislativo 1034 así lo establece y reconoce como tales a las siguientes:

a. La fijación concertada, de forma directa o indirecta, de precios o de otras condiciones comerciales o de servicio. 
b. La limitación o control concertado de la producción, ventas, desarrollo técnico o inversiones.

c. El reparto concertado de clientes, proveedores o zonas geográficas.

d. La concertación de la calidad de los productos, cuando no corresponda a normas técnicas nacionales o internacionales y que afecte negativamente al consumidor.

e. La aplicación concertada, en las relaciones comerciales o de servicio, de condiciones desiguales para prestaciones equivalentes, que coloquen de manera injustificada a unos competidores en situación desventajosa frente a otros.

f. Concertar, injustificadamente, la subordinación de la celebración de contratos a la aceptación de prestaciones adicionales que, por su naturaleza o arreglo al uso comercial, no guarden relación con el objeto de tales contratos.

g. La negativa, concertada e injustificada, de satisfacer demandas de compra o adquisición, o de aceptar ofertas de venta o prestación de bienes o servicios.

h. Obstaculizar, de manera concertada e injustificada, la entrada o permanencia de un competidor a un mercado, asociación u organización de intermediación.

i. Concertar injustificadamente una distribución o venta exclusiva.

j. Concertar o coordinar ofertas, posturas o propuestas, o abstenerse de estas en las licitaciones o concursos públicos o privados u otras formas de contratación o adquisición pública previstas en la legislación pertinente, así como en subastas públicas y remates.

k. Otras prácticas de efecto equivalente que busquen la obtención de beneficios por razones diferentes a las de una mayor eficiencia económica. (Decreto Legislativo 1034, 2008)

Para comprobar su existencia se requiere prueba directa.

Asimismo, constituyen prohibiciones absolutas las prácticas colusorias horizontales intermarca que no sean complementarias o accesorias a otros acuerdos lícitos y que tengan por objeto:

a. Fijar precios u otras condiciones comerciales o de servicio. 
b. Limitar la producción o las ventas, en particular, por medio de cuotas.

c. El reparto de clientes, proveedores o zonas geográficas.

d. Establecer posturas o abstenciones en licitaciones, concursos $\mathrm{u}$ otra forma de contratación o adquisición pública prevista en la legislación pertinente, así como en subastas públicas y remates. (Decreto Legislativo 1034, 2008)

Las prácticas colusorias horizontales distintas de las señaladas precedentemente constituyen prohibiciones relativas.

El Tribunal de Justicia de las Comunidades Europeas define las prácticas concertadas como "una forma de coordinación entre agentes económicos en la cual, sin que un acuerdo formal haya sido necesariamente concluido entre ellos, existe un nivel de cooperación práctica entre ellos que sustituye conscientemente los riesgos inherentes al proceso competitivo". Por su parte, la Corte Suprema de los Estados Unidos establece:

La voluntad común puede inferirse a partir de evidencia que tienda a excluir la posibilidad de que las partes hayan actuado cada una de manera independiente. Esto es, debe existir prueba directa o indirecta que lleve razonablemente a probar que las partes estuvieron comprometidas de manera consciente con un esquema común diseñado para conseguir un objetivo ilícito.

La Comisión de Defensa de la Libre Competencia de Indecopi (en adelante, la Comisión), en el Expediente 017-2015/CLC, emitió la Resolución 010-2017/CLC-INDECOPI, el 22 de marzo del 2017, y declaró que Kimberly-Clark Perú S. R. L. y Productos Tissue del Perú S. A. incurrieron en una práctica colusoria horizontal, en la modalidad de acuerdo para la fijación concertada de precios y condiciones comerciales en la comercialización de papel higiénico y otros productos de papel tissue en el territorio nacional durante el período 2005-2014. Se decidió sancionar a la primera con una multa de 42385,14 UIT y a la segunda con 25 726,28 UIT. Asimismo, se determinó que 14 personas naturales habían participado en el planeamiento, realización o ejecución de la práctica colusoria horizontal, a las cuales se les impusieron multas que en total ascendían a 279,84 UIT. 
En la referida resolución, además, se dejó sentado que en la práctica colusoria horizontal existe un elemento esencial, esto es, una conducta coordinada con el objeto o efecto de eliminar, restringir o limitar la competencia. Igualmente, se expresó que la Ley de Represión de Conductas Anticompetitivas distingue diversas formas de materializar estas conductas, entre las que se aprecian los acuerdos y las prácticas concertadas.

Esta resolución entiende por acuerdo que restringe la competencia a todo concierto de voluntades mediante el cual varios agentes económicos independientes se comprometen a realizar una conducta que tiene por objeto o efecto restringir la competencia. Pero, a su vez, se señala que el sentido de acuerdo tiene que ser muy amplio para que se pueda incluir cualquier conducta. Así, ante la falta de prueba directa, resulta necesario el uso de indicios y presunciones para demostrar la existencia de una voluntad común.

La Comisión define que las prácticas concertadas:

Consisten en aquellas conductas voluntariamente coordinadas que no pueden ser acreditadas por prueba directa de la celebración de un acuerdo entre agentes económicos con la finalidad de restringir o eliminar la competencia. Sin embargo, a partir de la actuación de dichos agentes en el mercado y de otras pruebas indirectas, se puede inferir como única explicación lógica la adopción de una estrategia concertada. Estas conductas se prueban mediante indicios y presunciones. (Resolución 051-2010/CLC, 2010)

En cuanto a la fijación concertada de precios (cárteles), la Comisión señala que no resulta necesario formular distinción entre hipótesis de fijación "directa" e "indirecta" de precios. La mención en el artículo 11.1 tiene por único objetivo que los administrados reconozcan que la fijación de precios resulta sancionable independientemente del mecanismo utilizado, en la medida en que una restricción en una variable competitiva esencial como el precio puede ser alcanzada por diversas vías, igualmente reprochables.

\section{Prácticas colusorias verticales}

Las prácticas colusorias verticales son los acuerdos, decisiones, recomendaciones o prácticas concertadas realizadas por agentes económicos que operan en planos distintos de la cadena de producción, distribución 
o comercialización, que tengan por objeto o efecto restringir, impedir o falsear la libre competencia.

Las conductas ilícitas verticales podrán consistir en los supuestos de conductas de efectos exclusorios y los acuerdos, decisiones, recomendaciones o prácticas concertadas llevadas a cabo por agentes económicos competidores entre sí que tengan por objeto o efecto restringir, impedir o falsear la libre competencia, según corresponda.

Para la configuración de una práctica colusoria vertical, se requiere que al menos una de las partes involucradas tenga, de manera previa al ejercicio de la práctica, posición de dominio en el mercado relevante. Asimismo, las prácticas colusorias verticales constituyen prohibiciones relativas.

\section{AnÁlisis de las Conductas anticompetitivas}

El legislador en el Decreto Legislativo 1034 establece que el análisis de las conductas anticompetitivas debe hacerse bajo la regla per se, dándoles la denominación de prohibición absoluta. Así, en su artículo 8, refiere que, para verificar la existencia de la infracción administrativa, es suficiente que la autoridad de competencia pruebe la existencia de la conducta. Estas prácticas resultan de mayor perjuicio a los consumidores, y como tal son graves, ya que por falta de competencia los precios les llegan muy elevados. Por ejemplo, la concertación o fijación de precios; los límites en las ventas precedidos generalmente de límites en la producción, reparto o división de mercados; y los acuerdos en las licitaciones. Estas conductas también son conocidas en el mundo como hard core cartels y, para eliminarlas del mercado, deben ser sancionadas drásticamente. En este caso, no resulta importante efectuar análisis alguno sobre el costo-beneficio de los efectos anticompetitivos y las probables eficiencias económicas, lo que sí es fundamental en las conductas examinadas bajo la regla de la razón.

Acudir a reglas que consideran una práctica per se ilegal (la per se rule), es decir que prohíben objetivamente el desarrollo de ciertas conductas independientemente de que en el caso concreto puedan o no generar un monopolio. La idea es evitar incurrir en costos administrativos para determinar la razonabilidad, cuando de ordinario la práctica no contribuye en nada al desarrollo de un mercado competitivo, y más bien, lo común es que dicha práctica esté restringiendo la competencia. (Bullard, 1994, p. 249) 
De la misma manera, en el artículo 9, como regla de la razón, ha establecido que, en los casos de prohibición relativa, para verificar la existencia de la infracción administrativa, la autoridad de competencia deberá probar la existencia de la conducta y que esta tiene o podría tener efectos negativos para la competencia y el bienestar de los consumidores. Se deben evaluar las características de cada mercado y las razones que los llevaron a aplicar la práctica restrictiva, hasta establecer si la restricción solo regula o promueve la competencia o, caso contrario, si promueve la supresión o eliminación de la misma. El esfuerzo para demostrar la irrazonabilidad de estas prácticas es mayor respecto a la regla per se, pues se tiene que probar que efectivamente produce un efecto dañino a la competencia en un mercado relevante. Se llega inclusive a pretender demostrar que la práctica restrictiva puede beneficiar al consumidor.

Se analiza entonces si es razonable o no que la práctica tenga un efecto anticompetitivo dadas las circunstancias. Se va entonces a un análisis caso por caso. Sin embargo, en muchas circunstancias, el análisis de la razonabilidad de una práctica es algo sumamente complejo y costoso. (Bullard, 1994, p. 248)

\section{Conclusión}

En materia de mercado y su protección, el estudio y campo de aplicación es muy amplio. Nos queda claro que nuestro país ingresó con más fuerza en este empeño desde el Acuerdo de Promoción Comercial entre Perú y Estados Unidos, vigente desde el 1 de febrero del 2009, por el cual el Estado peruano asumió el compromiso de tomar acciones que garantizaran que este y otros acuerdos beneficien a los consumidores y empresas nacionales. El Decreto Legislativo 1034 aprueba la Ley de Represión de Conductas Anticompetitivas para prohibirlas y sancionarlas, con la finalidad de promover la eficiencia económica en los mercados para el bienestar de los consumidores. Es aplicable a las conductas que produzcan o puedan producir efectos anticompetitivos en todo o en parte del territorio nacional, aun cuando dicho acto se haya originado en el extranjero.

No es fácil la tarea. Indecopi se encuentra en el esfuerzo de iniciar, de oficio o por denuncia, procedimientos sancionadores para eliminar del mercado las prácticas colusorias que limitan la competencia en perjuicio de los consumidores. Los órganos jurisdiccionales de este organismo del 
Estado que, desde el año 2015, revisan las resoluciones administrativas se encuentran subespecializados en temas de mercado, dentro de la especialidad contencioso-administrativa. La especialización en estos temas redunda en la resolución en menos tiempo (celeridad) de estos conflictos y de manera más certera y técnica, además de derecho por supuesto. Sin embargo, respecto a conductas anticompetitivas, son muy pocos los procesos judiciales iniciados. Nos encontramos a la espera de que mejore la detección de estas infracciones al mercado.

\section{REFERENCIAS}

Autoridad Vasca de la Competencia. (2013). Conductas colusorias. Recuperado de http://www.competencia.euskadi.eus/z02-cont ciud/es/contenidos/informacion/conductas_que_falsean/es_ colusori/conductas_colusorias.html

Becker, G. S. (2002). La naturaleza de la competencia. Themis, 44, 55-61.

Bullard, A. (1994). La legislación antimonopólica y el mito del muro de Berlín. Themis, 30, 243-260.

Decreto Legislativo 1034. (25 de junio del 2008). Recuperado del sitio de internet de Indecopi: https://www.indecopi.gob.pe/documents /51771/196578/dl1034.pdf/66c0472e-46de-4eb3-b872-7369c5279583

Espinoza, J. (2014). Introducción al derecho de la libre competencia. Lima: Escuela Nacional Indecopi, 2.

Gagliuffi, I. (2011). La evaluación de las conductas anticompetitivas bajo la regla per se o la regla de la razón. Revista de la Competencia y la Propiedad Intelectual, 7(13), 139-162.

López Rodríguez, C. E. (2008). ¿En qué consisten las conductas colusorias en el ámbito de la Ley de Promoción y Defensa de la Competencia 18.159 del 2007? Recuperado de http://www. derechocomercial.edu.uy/RespComte63.htm

Mankiw, G. (2007). Los diez principios de la economía. En Principios de economía (pp. 3-19). Madrid: Thomson.

Quintana, E. (2013). Libre competencia. Lima: Indecopi.

Resolución 0611-2013/SDC-INDECOPI. (2013). Tribunal de Defensa de la Competencia y de la Propiedad Intelectual. 
Resolución 051-2010/CLC-INDECOPI. (2010). Comisión de Defensa de la Libre Competencia. Recuperado del sitio de internet de Indecopi: https://www.indecopi.gob.pe/documents/20182/143803/ Res051-2010.pdf

Troncoso, C. (2012). Introducción a la economía. Introducción a la microeconomía. Montevideo: Facultad de Ciencias Económicas y de Administración, Universidad de la República. 
